\title{
ИНСТИТУТ НАСТАВНИЧЕСТВА В СИСТЕМЕ КОРПОРАТИВНОГО ОБУЧЕНИЯ
}

\author{
(c) 2021 Твердохлебова Татьяна Валерьевна \\ кандидат экономических наук, доцент \\ Институт управления бизнес-процессами \\ Сибирский федеральный университет, Россия, Красноярск \\ (c) 2021 Иванчук Анастасия Олеговна \\ кандидат технических наук, доцент \\ Институт горного дела, геологии и геотехнологий \\ Сибирский федеральный университет, Россия, Красноярск \\ (c) 2021 Левченко Лариса Владимировна \\ кандидат экономических наук, доцент, ст. научный сотрудник \\ Академия для одаренных детей (Наяновой), Россия, Самара \\ E-mail:lvls@mail.ru
}

В работе рассматривается современный институт наставничества как один из методов корпоративного обучения. Исследуются вопросы наставнической деятельности в современных компаниях, признаки и функции наставничества, требования к наставникам. Рассматривается общее направление развития института наставничества и системы наставничества в современных условиях. Приводятся примеры реализации опыта наставничества в российских и зарубежных компаниях.

Ключевые слова: наставничество, институт наставничества, корпоративное обучение, наставническая деятельность, человеческий капитал, андрагогика

Инновационная модернизация производственных процессов с целью поддержания конкурентоспособности компании и обеспечения ее лидерства на рынке приводит к тому, что многие предприятия и организации начали возрождать или создавать собственные корпоративные системы обучения. Эта практика позволяет решить многие проблемы в отношении кадрового обеспечения технических, технологических и экономических преобразований в современных российских условиях, когда имеет место недостаточная мобильность трудовых ресурсов и/или не обеспечивается требуемая динамика этой мобильности. В итоге многие работодатели вынуждены обновлять имеющиеся или разрабатывать новые подходы к обучению и повышению квалификации работников, например, внедрять в рамках корпоративного обучения системы повышения квалификации и переквалификации, дополнительного обучения по освоению смежных профессий, а также системы наставничества, кураторства и т.д. При этом многие специалисты и эксперты полагают, что в современных условиях достаточно эффектив- ная система наставничества может быть создана и успешно реализована практически на любом российском предприятии при любой стадии его организационного развития, в компаниях любого масштаба и любой отрасли*.

В этой связи считаем важным и своевременным рассмотреть вопросы, связанные с развитием института наставничества и системы наставничества на предприятиях, в том числе вопросы о роли и значении наставничества в современных условиях, об эффективной организации наставнической деятельности, механизмах ее поощрения и мотивации. Также актуальными сегодня остаются исследования самого наставнического труда, его элементов и функций, что требует дополнительной разработки системы организации наставнической деятельности и контроля за ее осуществлением.

Прежде всего следует отметить, что в нормативных источниках и научной литературе можно встретить различные подходы к определению самого термина «наставничество». Так, например, в документах Министерства труда и социальной защиты Российской Федерации

\footnotetext{
* Масалимова А. Р. Корпоративная подготовка наставников. - Казань: Изд-во «Печать-Сервис XXI век», 2013. С. 123.
} 
отмечается, что «наставничество является кадровой технологией, обеспечивающей передачу посредством планомерной работы знаний, навыков и установок от более опытного сотрудника - менее опытному»*. В тоже время наставничество рассматривается как действенный и значимый механизм воспроизводства кадрового потенциала организации ${ }^{* *}$.

В научной литературе институт наставничества часто характеризуют как механизм социально-профессиональной адаптации новых кадров предприятия, который предполагает их производственное обучение или переобучение более опытными и квалифицированными работниками без отрыва от производства. В тоже время институт наставничества представляет собой и особый практико-ориентированный метод обучения, при котором наставник помогает быстрее адаптироваться к условиям работы на новом месте, осуществляет передачу знаний и практического опыта «новичкам», проводит ситуативные консультации по техническим, технологическим или организационным вопросам, инструктирует в ходе рабочего процесса, помогает освоить «секреты» профессионального мастерства на личном примере, осуществляет совместный анализ результатов трудовой деятельности, проверяет качество и уровень выполнения работ и деятельности, отслеживает профессиональное развитие нового сотрудника, непосредственно участвует в оперативном решении возникающих производственных проблем, что позволяет избежать многих грубых ошибок и предотвратить возможные аварийные ситуации.

Наставничество как метод обучения персонала признан эффективным в связи с тем, что содержит в том числе неявные знания, получаемые от наставника, и позволяет передавать личный опыт наставника без посредников ***.

Наставничество предполагает своеобразное сотрудничество в обучении и взаимно обогащающее общение (менторинг) между наставником и обучаемым работником (менти), при котором наставник-ментор передает свой личный опыт и практические знания, развивая при этом свой профессиональный и лидерский потенциал. Кроме того, наставник помогает новым сотрудникам быстрее адаптироваться в трудовом коллективе и к его корпоративным традициям. Все выше отмеченное позволяет сказать, что наставничество является также и особым социальным институтом, в рамках которого формируются отношения сотрудничества и корпоративная культура, что является важной позитивной предпосылкой для устойчивого долгосрочного развития любой компании.

Характеризуя институт наставничества, можно выделить несколько его значимых признаков, среди которых:

во-первых, прикладной подход - основополагающий, при котором институт наставничества сфокусирован на непосредственно производственной деятельности обучаемого работника, на формировании его прикладных профессиональных компетенций, на освоении им практического функционала в рамках профессии при посредстве наставника;

во-вторых, гибкость - в отличие от формализованного учебного процесса, осуществляемого по заданным стандартам, четким учебным планам и учебным графикам, рекомендованным методикам, наставничество же предполагает большую гибкость, изменчивость и вариативность в применении наставником тех или иных приемов, методов и форматов обучения при передачи профессиональных знаний и практических навыков, при освоении обучаемым работником прикладных профессиональных компетенций;

в-третьих, индивидуальный подход - именно институт наставничества позволяет учитывать в первую очередь индивидуальные потребности, запросы и задачи, стоящие перед конкретным работником на новом рабочем месте в реальных условиях, предлагает ему адресный подход с учетом уже имеющихся у работника индивидуальных компетенций и производственного опыта;

в-четвертых, адаптивность - посредством наставничества происходит безболезненное и оперативное приспособление работников с

\footnotetext{
* Министерство труда и социальной защиты Российской Федерации. Методический инструментарий по применению наставничества на государственной гражданской службе. М., 2013. С.5.

** Кларин М. В. Современное наставничество: Новые черты традиционной практики в организациях XXI века// Экономическая теория, анализ, практика. 2016. № 5. С. 92.

*** Соловьёв Д. П. Обучение и развитие персонала: учеб. пособие / Д. П. Соловьёв, Л.А. Илюхина. Самара: Изд-во Самар. гос. экон. ун-та, 2019. 204 с.
} 
внешнего рынка к особенностям и условиям работы на новом рабочем месте, достаточно быстрое адаптирование в новом трудовом коллективе и более «естественное» и быстрое принятие «новичком» сложившихся в организации единых стандартов работы, корпоративных традиций и корпоративной культуры компании.

По имеющимся статистическим данным, в российских компаниях в настоящий момент наибольший удельный вес среди применяемых методов внутреннего корпоративного обучения занимает наставничество (78\%)*.

Институт наставничества выполняет в компаниях и на предприятиях определенные функции:

- организационно-управленская функция: управление обучающим процессом новых/молодых сотрудников, управление и руководство проектами молодых специалистов, их дополнительная мотивация;

- социально-педагогическая функция: социальное, психологическое и профессиональное развитие «новичков», их адаптация в коллективе, знакомство с корпоративной культурой, раскрытие их потенциала, выбор и построение индивидуальной обучающей и профессиональной траектории;

- организационно-методическая функция: подготовка и разработка учебно-методических пособий и иных материалов по наставничеству, эффективных методов и методик обучения и развития, построения успешных траекторий обучения, развития и карьерного роста и др.;

- информационно-консультационная функция: эффективная передача наставником значимой информации и рациональных приемов, оказание консультационной помощи и поддержки, сохранение имеющегося положительного профессионального и коммуникационного опыта и др.;

- коррекционно-реорганизующая функция: постоянное отслеживание новых тенденций и обновление материалов, технологий, методов обучения молодых сотрудников предприятия и др.***

Наставничество также является эффективной формой внутреннего обучения в компании. Как известно наставничество является важным элементом и формой системы внутреннего корпоративного обучения (помимо него широко практикуются семинары и лекции, инструкторско-методические занятия, круглые столы и конференции, тренинги формирования навыков, ротация кадров, коучинг и др.).

Внутреннее обучение персонала представляет собой его обучение силами самой организации и в основном ориентировано на обучение персонала низшего или среднего звена, на подготовку или переподготовку кадров по рабочим профессиям. Положительные стороны такого обучения - это прежде всего, его практическая направленность, относительно небольшие издержки на обучение, более полный учет специфики организации, четкий контроль за всем обучающим процессом и его результативностью, а также возможность внесения быстрых корректив в процесс и содержание обучения в связи с изменившимися задачами. Среди отрицательных моментов внутрифирменного обучения обычно выделяют невозможность обменяться информацией с работниками других организаций, позаимствовать опыт решения тех или иных производственных проблем у коллег из других компаний.

В современных крупных компаниях в рамках корпоративного обучения получило развитие наставничество как самостоятельная система, обеспечивающая практическую подготовку рабочих под руководством наставника ${ }^{* * * *}$. При этом наставник - это всегда работник той же компании, но опытный и высококвалифицированный, проводящий без отрыва от производства работу по производственному обучению, стажировке, консультированию, практике, а также адаптации нового сотрудника.

Система наставничества, как и политика предприятия в области обучения персонала должна проводиться через разработку и четкую

\footnotetext{
* Безлепкина Е.Современные методы обучения персонала. URL: http:/www.ngpc.ru/forum2010/Articles/ Learnining\%20methods.pdf

** Масалимова А. Р. Корпоративная подготовка наставников. - Казань: Изд-во «Печать-Сервис XXI век», 2013. C. 72 .

*** Карпенко О.А., Левченко Л.В.Изменения в преподавательской деятельности на современном этапе общественно-экономического развития // Современная наука: перспективы, достижения и инновации. Материалы III Международной научно-практической конференции. Составители: Б. М. Насибулина, Т. Ф. Курочкина, Р. С. Мунер. 2020. С. 102-105.
} 
реализацию нормативных документов, в числе которых важная роль отводится положению о наставничестве. Кроме того, система наставничества включает целый комплекс инструментов для организации и поддержания работы наставников: регламент наставничества, систему подготовки наставников, систему материальной и не материальной мотивации наставников, инструменты поддержки работы наставников и др.

В крупных компаниях с развитой системой наставничества также существует программа повышения квалификации для преподавателейнаставников, которые должны: знать основы андрагогики, уметь структурированно описать деятельность должности и сформировать модель компетенций, уметь разрабатывать учебнометодические материалы, знать и применять интерактивные методы в обучении.

Наряду с этим, стоит отметить, что само слово «наставник» не идентифицировано в каком-либо законодательном или правоприменительном акте РФ. В нашей стране на каждом предприятии и в различных регионах и городах существуют различные права и обязанности наставников, разнообразные требования к образованию и опыту работы, к его подготовке, к личностным качествам и др. Однако имеющийся в этом направлении положительный опыт передовых российских компаний не оставляет сомнений в том, что введение наставничества на предприятиях позволяет существенно повышать эффективность деятельности компании, обеспечивая тем самым свои потребности в квалифицированных кадрах.

Современное наставничество не ограничивается лишь подготовкой рабочих, оно также необходимо при подготовке инженерных профессий и специальностей, информационных и специалистов в сфере IT-технологий, техников и технологов и т.д. Обучению и наставничеству также подлежит, и даже в большей степени, проведение исследовательской работы, проектной, конструкторской, инновационной и иной деятельности*.

В этой связи современным наставникам приходится осваивать новые качественные компетенции, навыки и приобретать новые профессиональные знания. В данном случае речь идет, например, о навыках создания практикоориентированной образовательной среды для наставничества, педагогического проектирования, непрерывного сопровождения «новичков» и стажеров, организации их самостоятельной работы, формирования и самостоятельного оценивания их компетенций, построения и развития стажеров и обучаемых в соответствии с индивидуально построенной образовательной траекторией и программой и т.д.

Следует учитывать, что эффективная деятельность наставника в современной компании во многом зависит от его профессионализма, уровня квалификации и производственного опыта, но также еще определяется и наличием сформированного определенного набора психолого-педагогических и методических компетенций, которым, как правило, необходимо предварительно обучать. Поэтому многие эксперты и специалисты-практики кадровых служб полагают, что наставникам, которые в какой-то степени являются и педагогами для своих подопечных, необходимо педагогическое обучение в определенном объеме и по определенному перечню проблем. В нашей стране в советское время этот вопрос не возникал: на эту тему публиковались и многочисленные исследования о педагогической системе наставничества, педагогическом мастерстве, заводской или производственной педагогике. В последние годы в связи с возвращением интереса к наставничеству и развитием опыта его внедрения на ведущих российских предприятиях вновь встает вопрос о подготовке наставников, в том числе с учетом их педагогической подготовки.

В настоящее время в ряде российских регионов и областей начала формироваться положительная практика внедрения системы наставничества на крупных предприятиях, а также системы дополнительной профессиональной и педагогической подготовки наставников. Затраты на формирование и обеспечение системы наставничества во многих случаях финансово окупаются и признаны эффективными вложениями. Прежде всего в этой связи следует отметить Республику Татарстан, Свердловскую и Тюменскую области, в которых активно развиваются взаимодействие и сотрудничество между профессиональными образовательными учреждениями, педагогическими вузами, организациями по повышению квалификации преподавателей и мастеров производственного об-

\footnotetext{
* Наставничество на производстве. НИ центр профессионального образования и систем квалификаций ФИРО РАНХиГС. М.: 2019. С. 27-28.
} 
учения, наставников на производстве. При этом стоит отметить, что в программах обучения наставников для производства были выделены специальные разделы, связанные с развитием и реализацией у них не только профессиональных, но также и индивидуальных личностных, психологических, социальных, педагогических и методических знаний, навыков и компетенций.

В нашей стране также существует положительный опыт обмена опытом и взаимодействия с зарубежными компаниями по вопросам наставничества, например, обмен опытом российских компаний с немецким участием (Гиперглобус; Баутекс ОАО Фольксваген Групп Рус; и др.) с Российско-Германской внешнеторговой палатой и др.

Заметим, что во многих крупных российских организациях и предприятиях - отраслевых лидерах производства сформирована и успешно функционирует система наставничества, которая охватывает практически все иерархические уровни, начиная от сотрудников рабочих профессий, специалистов среднего звена и, заканчивая руководящими работниками предприятия.

В связи с тем, что наставничество требует от человека соответствующего времени, труда, определенных моральных, психологических и педагогических качеств, оно должно стимулироваться и поощряться. Для стимулирования и поощрения наставничества широко используются административные (нематериальные) и финансовые (материальные) меры: доплаты наставникам, снижение для них производственных показателей, премирование, информационное освещение деятельности наставников и их достижений во внутренних корпоративных СМИ, присвоение почетного статуса, объявление благодарности приказом руководства компании, награждение почетными грамотами и т.д. Например, на Новокуйбышевском нефтеперерабатывающем заводе Самарской области (Роснефть) внедрена специальная программа Программа наставничества и развития рабочих ресурсов, благодаря которой закрепляется официальный статус наставника. Обучаемый по окончании процесса наставничества проходит установленные формы контроля, по результатам которых наставникам выплачивается денежное вознаграждение. Также материальное стимулирование наставника предусмотрено в случае победы его подопечных на конкурсах и чемпионатах профессионального мастерства*.

Эксперты подтверждают, что в большинстве российских компаний в 90\% случаев за наставническую деятельность доплачивают в той или иной форме. В качестве примера успешного материального стимулирования можно привести также Казанский государственный казенный пороховой завод, где существует форма материального стимулирования при подготовке молодых рабочих: ежемесячная доплата их наставникам варьируется от 5\% до 15\% от оклада при подготовке одного молодого рабочего, от оклада при подготовке двух и более молодых рабочих до $20 \%$.

ПАО «Татнефть» также является хорошим примером: наставническая деятельность здесь поощряется как нематериально - почетными грамотами, благодарственными письмами и т.д., так и материальным вознаграждением в виде премии за работу со вновь принятыми работниками или в виде ежемесячной надбавки к заработной плате за каждого стажера.

Институт наставничества применяется в России и на государственной службе, а в последние годы существенно повысился интерес к его развитию. Наставничество в этой сфере охватывает передачу профессиональных знаний и навыков, индивидуального опыта, служебных нюансов, адаптацию в коллективе и в служебной деятельности и др., регламентируется документально и применяется ко всем новым сотрудникам или специалистам, входящим в кадровый резерв, из которого приходящим на службу**.

Следует отметить, что в мировой практике институту наставничества на производстве уделяют все больше внимания, ориентируясь при этом на обучение всего коллектива работников предприятия. В системе наставничества разработаны и успешно применяются программы обучения не только для рабочих профессий, но и для уровня бакалавриата. Кроме того, в рамках общей иерархии программ для наставников от

\footnotetext{
* Сборнова Е. НК НПЗ: Институт наставничества - школа профессионализма. Режим доступа: http:// http:// www.samara.kp.ru/daily/26556/3573070/ (дата обращения: 11 октября 2016 года).

** Постановление Правительства РФ от 7 октября 2019 г. N 1296 «Об утверждении Положения о наставничестве на государственной гражданской службе Российской Федерации»
} 
основного уровня дополнительного профессионального образования и до высшего также имеется профессиональная магистратура. Подобные программы, как правило, носят модульный характер и позволяют наставнику при необходимости и желании самому «расти» в своей профессиональной деятельности, повышать уровень своего наставнического мастерства. При этом в зарубежной практике к наставничеству подходят также и как к важной и необходимой составляющей корпоративного духа фирмы.

Итак, современное развитие технологий и производственных отношений приводит к необходимости создания на предприятиях разви- той системы наставничества, которая позволяет более ясно и наглядно, быстро и эффективно передавать знания и опыт работникам, обеспечивая оптимальное использование времени и ресурсов, что позволяет предприятию или организации устойчиво развиваться в условиях динамично меняющейся внешней среды. Институт наставничества, являясь практическим (практико-ориентированным), гибким и экономически эффективным методом обучения и адаптации работников, может успешно реализовываться в организациях и компаниях любого масштаба, находящихся на любой стадии организационного развития.

\section{Библиографический список}

1. Безлепкина E. Современные методы обучения персонала. Режим доступа: http://www.ngpc.ru/forum2010/ Articles/Learnining\%20methods.pdf (дата обращения 18.09.2021)

2. Карпенко О.А., ЛевченкоЛ.В. Изменения в преподавательской деятельности на современном этапе общественно-экономического развития // Современная наука: перспективы, достижения и инновации. Материалы III Международной научно-практической конференции. Составители: Б. М.Насибулина, Т. Ф. Курочкина, Р. С. Мунер. 2020. С. 102-105.

3. Килина И.А., Пфетцер А. А., Осипова Н.В. Развитие института наставничества в Кузбассе// Образование. Карьера. Общество. 2018. № 2(57). С. 54-59.

4. Кларин М.В. Современное наставничество: Новые черты традиционной практики в организациях XXI века// Экономическая теория, анализ, практика. 2016. № 5. С. 92-112.

5. Коучинг, менторинг, наставничество: сходства и различия // Вестник АРК. 2018. № 3 Режим доступа: https:// imcoach.su/kouching_mentoring_nastavnichestvo_skhodstva_i_razlichiya (дата обращения 17.10.2021)

6. Левченко Л.В., Карпенко О.А. Человеческий капитал и современные тенденции его развития // Вопросы экономики и права. 2019. № 137. С. 36-43

7. Масалимова А. Р. Корпоративная подготовка наставников. - Казань: Изд-во «Печать-Сервис XXI век», 2013. 183 с.

8. Министерство труда и социальной защиты Российской Федерации. Методический инструментарий по применению наставничества на государственной гражданской службе. М., 2013.

9. Наставничество на производстве. НИ центр профессионального образования и систем квалификаций ФИРО РАНХИГС. М.: 2019, 58 с.

10. Осипов П.Н., Ирисметова И. И. Развитие наставничества как средства подготовки кадров// Казанский педагогический журнал. 2019. № 1. С.100-105.

11. Осипов П.Н., Ирисметова И.И. Наставничество как объект научных исследований// Профессиональное образование и рынок труда.2020. № 2. С. 109-115.

12. Постановление Правительства РФ от 7 октября 2019 г. N 1296 «Об утверждении Положения о наставничестве на государственной гражданской службе Российской Федерации»

13. Сборнова Е. НК НПЗ: Институт наставничества - школа профессионализма. Режим доступа: http:// http:// www.samara.kp.ru/daily/26556/3573070/ (дата обращения: 11 октября 2016 года).

14. Соловьёв Д. П. Обучение и развитие персонала: учеб. пособие / Д. П. Соловьёв, Л.А. Илюхина. Самара: Издво Самар. гос. экон. ун-та, 2019. 204 с.

15. Шкерин А.В. Наставничество как инструмент самообучающейся организации// Вестник Нижегородского университета им. Н.И. Лобачевского. Серия: Социальные науки, 2018, № 2 (50), с. 109-114. 